\title{
The Diagnosis of Upper-Level Humidity ${ }^{1}$
}

\author{
Donald A. Chisholm, John T. Bali, Keith W. Veigas ${ }^{2}$ and Paul V. Luty \\ The Travelers Research Center, Inc., Hartford, Conn.
} (Manuscript received 10 January 1968, in revised form 20 March 1968)

\begin{abstract}
Northern Hemisphere surface-synoptic and radiosonde data from November 1961 through February 1962 are used to develop diagnostic relationships between surface-observed variables at a single station and the dewpoint spread at the $850-, 700-, 500$ - and $400-\mathrm{mb}$ levels above that station. The approach consists of two steps : 1) the isolation within a decision-tree framework of those cases for which individual surface-observed variables yield highly reliable estimates of upper-level humidity, and 2) the application of a statistical technique (Regression Estimation of Event Probabilities) to the remaining cases to derive equations yielding probabilities of occurrence of specified categories of dewpoint spread. This approach yields useful diagnostic information with a quantitative measure of reliability.
\end{abstract}

\section{Introduction}

This paper describes research to develop the means for obtaining an improved hemispheric humidity analysis through the use of diagnostic data as a supplement to radiosonde observations. Because the radiosonde stations in the Northern Hemisphere are few in number (about 600) and unevenly distributed, there are relatively few observations of upper-level humidity, especially over oceans and sparsely inhabited land areas. To obtain an adequate depiction of the distribution of humidity in such regions, we must attempt to make inferences from other data sources, in this case, from surface data. If reliable relationships can be developed between upper-level humidity and surfaceobserved variables, the required diagnostic data can be derived from routine surface-synoptic and marinesynoptic observations (made at about 4000 stations in the Northern Hemisphere). Such data would then be combined with radiosonde data to give the best possible analysis of the humidity field.

There has been little reported research on relating surface-observed variables to upper-level humidity though there has been earlier work concerned with relating synoptic features (moisture, pressure and temperature patterns) to cloudiness.

Mason and Howorth (1952) examined cases of drizzle and continuous and intermittent rain and snow in North Ireland; they found marked differences in cloud thickness and temperature at cloud-top level between different precipitation types. Mook (1955) showed that

\footnotetext{
1 This research was sponsored by the Electronics Systems Division of the U. S. Air Force under Subcontract No. 15107 to Contract No. 4F19(628)-3437 (United Aircraft Corporation, Prime Contractor).

${ }^{2}$ Present affiliation: Eastern Region, Weather Bureau, ESSA, Garden City, Long Island.
}

the occurrences of drizzle from precipitating stratiform clouds decrease rapidly as cloud thickness increases.

In Air Weather Service Manual 105-124 (1961) and other publications, it is pointed out that regions having continuous precipitation and overcast middle cloud are generally characterized by areas at $500 \mathrm{mb}$ having a dew point spread $\leqslant 4 \mathrm{C}$.

Other studies have been aimed at developing a relationship (usually linear) between some measure of moisture and cloud amount. Thus, Smagorinsky (1960) derived an empirical expression for obtaining cloud amount in low, middle and high layers from relative humidity, and Essenwanger (1962) compared the frequency and vertical extent of overcast stratiform clouds at Berlin with variations in the vertical of the relative humidity profile. However, none of these studies established a reliable means of depicting upper-level humidity from surface-observed variables.

\section{Diagnostic approach}

The diagnostic approach consisted of 1) isolating within a decision-tree framework those cases for which individual surface-observed variables (or simple combinations thereof) yield highly reliable estimates of upper-level humidity, and 2) applying a statistical technique developed by Miller (1964), Regression Estimation of Event Probabilities (REEP), to the remaining cases to derive equations yielding probabilities of occurrence of specified categories of dewpoint spread (DPS). A separate set of decision-tree and REEP relationships was developed for each of the mandatory constant pressure levels $(850,700,500$ and $400 \mathrm{mb})$.

Our goal was to find the combination of surfaceobserved variables that yields the greatest number of reliable estimates of moisture content. Because there 
TABLE 1. Surface variables used in diagnostic studies.

\begin{tabular}{|c|c|c|c|c|}
\hline \multicolumn{3}{|c|}{ Variable } & \multicolumn{2}{|c|}{ Usage } \\
\hline Name & Symbol & Units & $\begin{array}{l}\text { Decision } \\
\text { tree }\end{array}$ & $\begin{array}{l}\text { Statis- } \\
\text { tical }\end{array}$ \\
\hline Wind direction & $\mathrm{DD}$ & $\operatorname{deg}$ & no & yes \\
\hline Wind speed & $\mathrm{ff}$ & $\mathrm{kt}$ & no & yes \\
\hline Pressure & $\mathrm{P}$ & $\mathrm{mb}$ & no & yes \\
\hline Temperature & $\mathrm{T}$ & ${ }^{\circ} \mathrm{C}$ & no & yes \\
\hline Dewpoint & $T_{d}$ & ${ }^{\circ} \mathrm{C}$ & no & yes \\
\hline Dewpoint spread & DPS & ${ }^{\circ} \mathrm{C}$ & no & yes \\
\hline Visibility & VV & $\mathrm{mi}$ & no & yes \\
\hline Present weather & ww & 一 & yes & yes \\
\hline Past weather & W & - & yes & yes \\
\hline Total cloud amount & $\mathrm{N}_{\mathrm{T}}$ & tenths & yes & yes \\
\hline Low cloud amount & $\mathrm{N}_{\mathrm{h}}$ & tenths & yes & yes \\
\hline Low cloud height & $\mathrm{h}$ & $\mathrm{ft}$ & yes & yes \\
\hline Low cloud type & $\mathrm{C}_{\mathrm{L}}$ & - & yes & yes \\
\hline Middle cloud type & $\mathrm{C}_{\mathrm{M}}$ & - & yes & yes \\
\hline High cloud type & $\mathrm{C}_{\mathrm{H}}$ & - & yes & yes \\
\hline Pressure change & app & $\mathrm{mb}$ & yes & yes \\
\hline
\end{tabular}

is an almost unlimited number of combinations, we considered several of the most likely possibilities as discussed in Section 4.

The threshold value separating reliable estimates from unreliable estimates of moisture content was determined by considering the accuracy of the radiosonde element, surface observational capability, radiosonde representativeness, permissible diagnostic error,
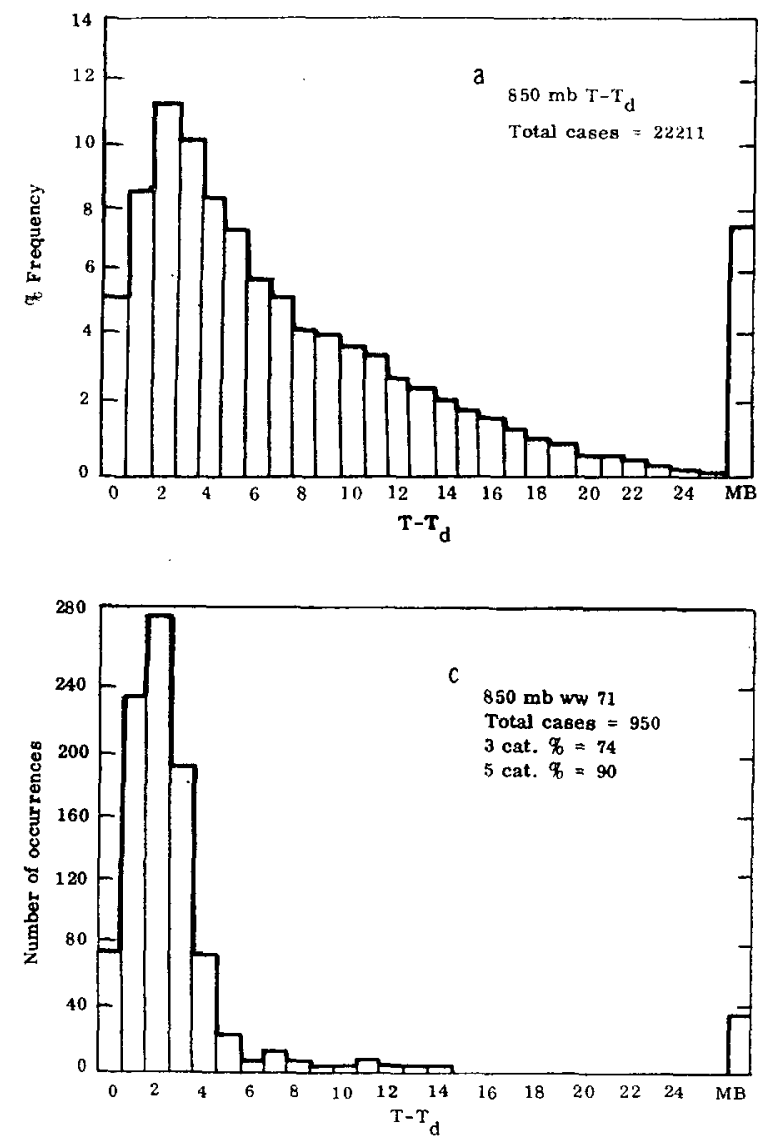

humidity climatology at each of the constant pressure levels, and data sample size of variable being considered.

Histograms were developed for each variable listed as a "yes" under decision-tree usage in Table 1 and the frequency distribution of DPS for each was evaluated. Figs. 1b-d illustrate a moderately reliable, a highly reliable, and an unreliable relationship, respectively, between a surface-observed variable category and upper-level humidity (in this case at $850 \mathrm{mb}$, but applicable to all levels). The climatology of $850-\mathrm{mb}$ DPS for the sample is given in Fig. 1a. Histograms and other detailed material used to develop the decision-tree relationships can be found in Ball et al. (1965a).

\section{Data}

A collection of upper air and surface-synoptic observations for the period 0000 GMT 22 November 1961 to 1200 GMT 14 March 1962 was available. Every fifth time period was set aside as independent data with which to test derived relationships. The processed data sample (observations at both 0000 and $1200 \mathrm{GMT}$ ) comprised 23,552 dependent and 5507 independent cases.

The method used to encode upper air data made it impossible to differentiate a motorboating condition
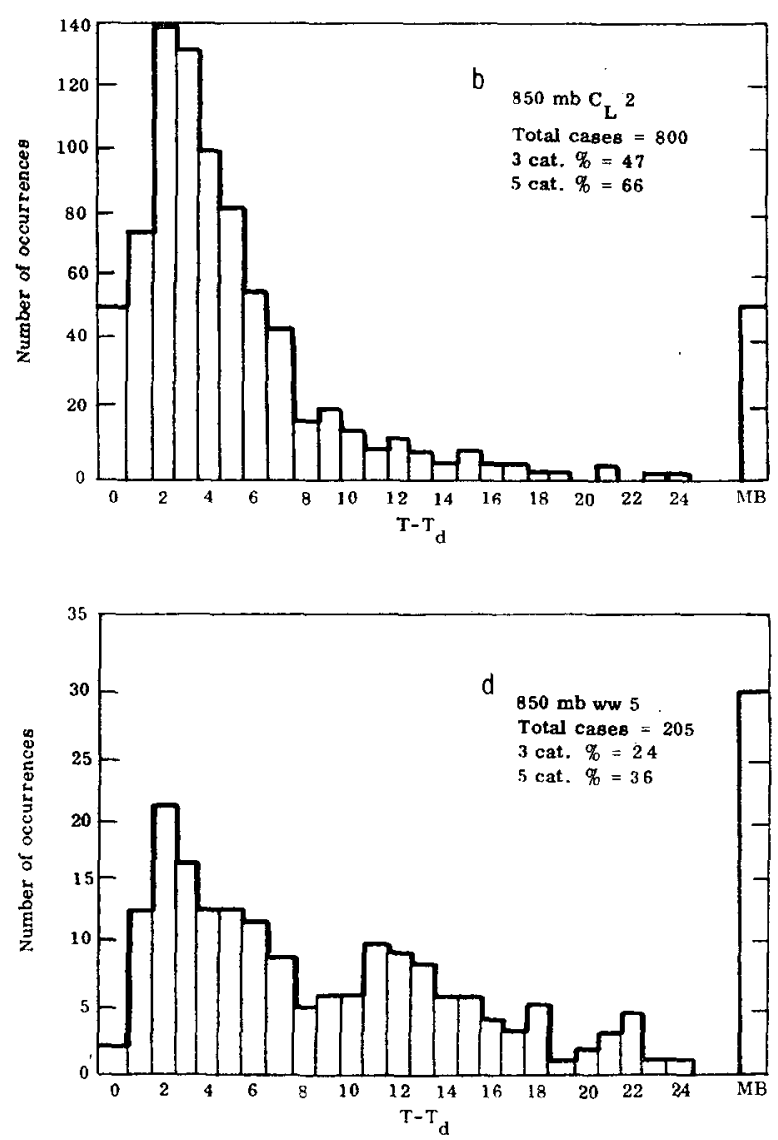

FTG. 1. 850-mb DPS climatology, a., and examples of histograms, b.-d. 
TABLE 2. Number of acceptable cases $(850 \mathrm{mb})$.

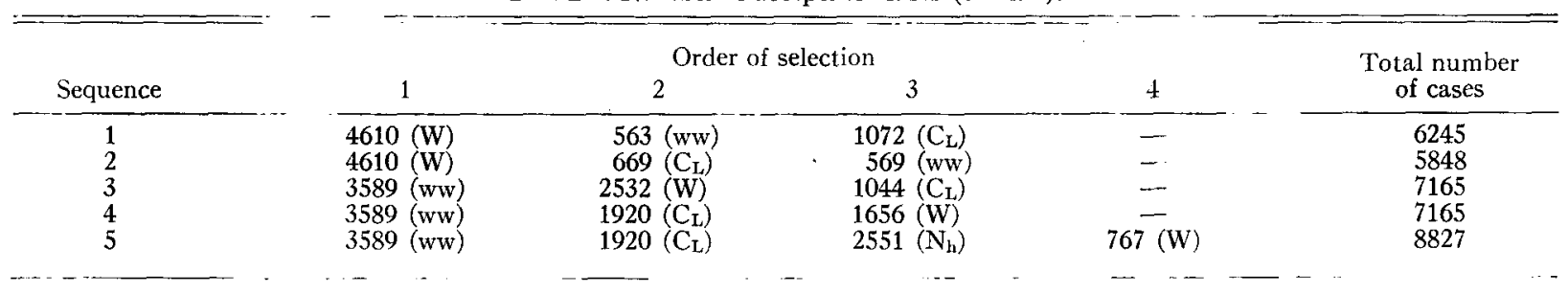

from a missing-value condition. Considering all such cases as a missing value would bias the data sample; thus, based on a study of 200 plotted radiosonde observations, those missing-value reports associated with both a reported height and temperature were assumed to have a motorboating condition and, for diagnostic studies, were assigned a representative dewpoint spread value of $30 \mathrm{C}$.

\section{Decision-tree evaluation and results}

850-mb decision tree. The threshold value established for the $850-\mathrm{mb}$ level allowed acceptance of a relationship in which $45 \%$ or more of the cases fell within three consecutive 1C-DPS intervals and $60 \%$ or more fell within five such intervals. Analysis of the dependent data sample suggested that present-weather, pastweather, and low-cloud type variables contain many mutually exclusive types that are very highly related to the $850-\mathrm{mb}$ humidity. The selection of the presentweather types was enhanced by within-variable grouping of types representing similar synoptic situations.

It was necessary to screen a large number of alternatives and decide which sequence of utilizing the variables would give the most usable results. Table 2 summarizes the number of cases containing acceptable relationships in each of the five sequences attempted. Because the fifth sequence yielded over 1500 more reliable cases than any of the others, it was selected as the 850 $\mathrm{mb}$ decision tree.

Table 3 gives each of the variable types in the fifth sequence, plus 1) modal DPS, 2) the percentage of cases within the five 1C-DPS intervals containing the greatest number of cases and the mid-point of this interval, and 3 ) the total number of cases of the observed type. The associated decision tree is shown in Fig. 2 wherein the diagnosed DPS's are the midpoints of the five $1 \mathrm{C}$ intervals in Table 3.

TABLE 3. Selected surface variable types for $850-\mathrm{mb}$ decision tree.

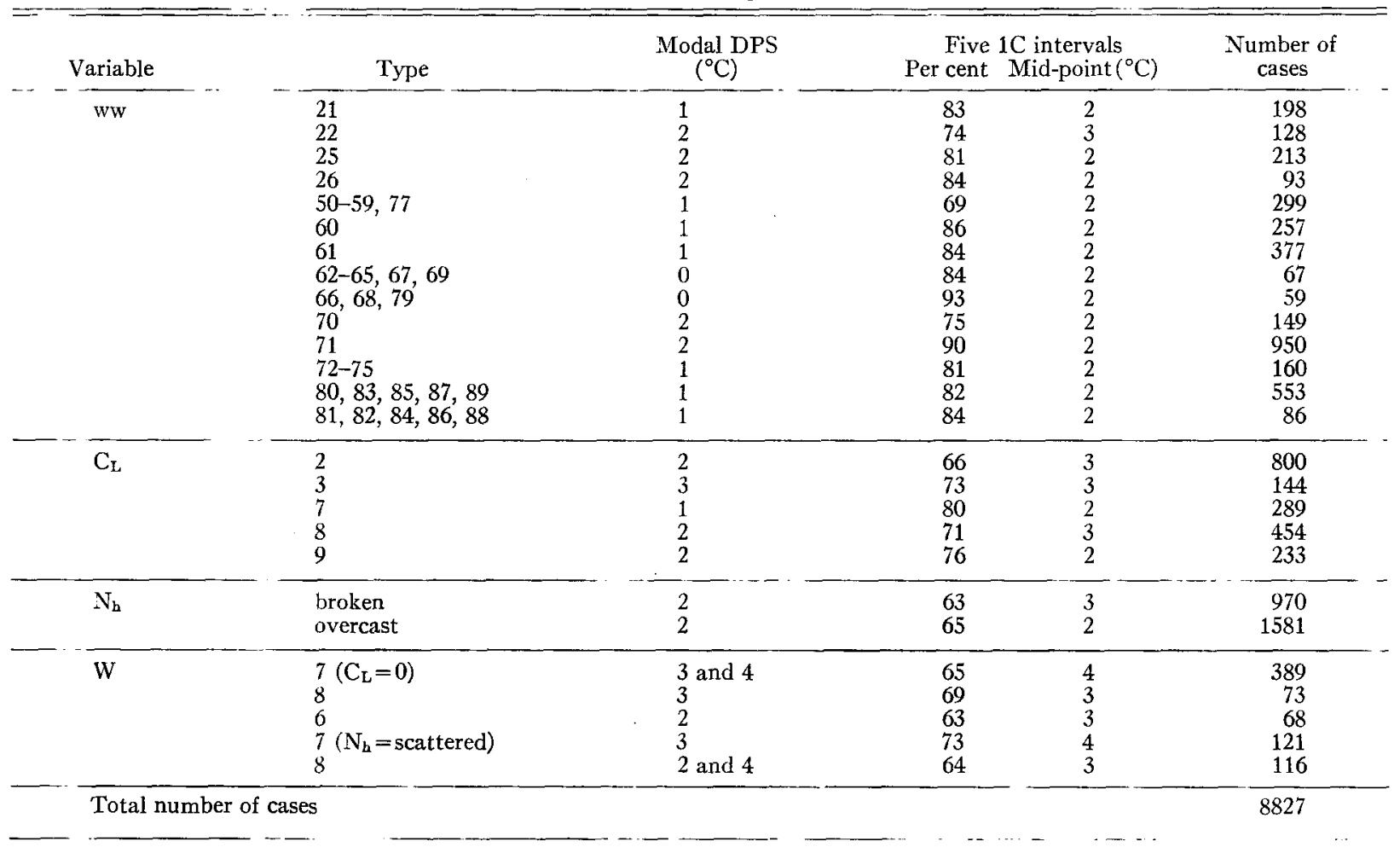




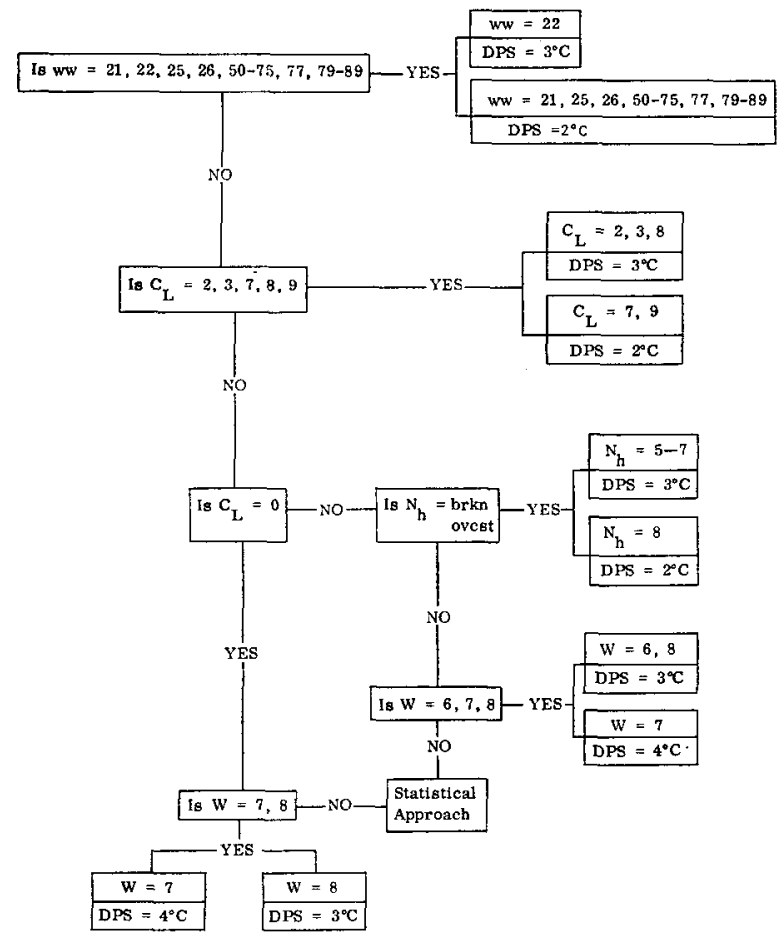

FIg. 2. $850-\mathrm{mb}$ decision tree.

The first variable considered is present weather. Of the $100(00-99)$ types of present weather, 42 yield reliable estimates of the 850 -mb DPS, either individually or in combination with other types. All 42 types represent precipitation either falling at the time of the observation (50-89) or within the past hour $(21,22,25,26$, .

The present-weather types generally associated with dry conditions at $850 \mathrm{mb}$ do not yield a distribution skewed enough at the dry end of the DPS range to give an acceptable relationship. This is also true for other histograms of 850-mb DPS obtained with low-cloud type, low-cloud amount, and past weather. The cases containing the selected present-weather types were removed from the data sample prior to examining lowcloud type. Five of the nine types of low cloud give distributions indicating reliable estimates of the $850-\mathrm{mb}$ DPS.

The developmental sample size was further reduced by extracting the cases containing low-cloud types 2,3 , 7,8 and 9. It was felt that useful relationships could be gleaned from the remaining sample if the amount of low cloud $\left(\mathrm{N}_{h}\right)$ was taken into account. The sample was divided into two parts, one containing the remaining cases of reported low clouds (types 1, 4, 5 and 6), and the other containing cases of no reported low cloud. The cases with a reported low cloud were separated into three types of low-cloud amount: scattered (1/8 to 4/8), broken $(5 / 8$ to $7 / 8)$, and overcast (8/8). Both broken and overcast yield reliable estimates of the 850 $\mathrm{mb}$ DPS and are summarized in Table 3.
After the cases of broken or overcast low-cloud types $1,4,5$ and 6 had been removed, an analysis of the remaining cases with respect to past weather was done in two parts, i.e., those cases containing the scattered lowcloud types and those containing reports of no low clouds. The selected past-weather types are summarized in Table 3.

At this point, further reliable relationships could not be established using the decision-tree procedure. The remaining cases, called the "residual sample," were then examined using the REEP technique. The results are described in Section 5.

700-, 500- and 400-mb decision trees. The decisiontree procedures for diagnosing DPS at the 700-, 500and 400-mb levels are given in Figs. 3, 4 and 5, respectively. The "MB" in the latter two figures refers to a diagnosis of dry conditions, i.e., a DPS $\geq 15 \mathrm{C}(500 \mathrm{mb})$ or $\geq 20 \mathrm{C}$ ( $400 \mathrm{mb})$, or motorboating. The given diagnosed DPS is the mid-point of the five consecutive $1 \mathrm{C}$ intervals containing the greatest number of observations.

The development of the 700-mb decision tree and results obtained were similar to that for $850 \mathrm{mb}$. Again, only moist diagnoses were possible. The total number of diagnoses made was 5011, compared to 8827 for $850 \mathrm{mb}$.

Because the relationships between $500-$ and $400-\mathrm{mb}$ humidity and surface-observed variables are not as strong as at lower levels, the data sample was divided into moist and dry sub-samples determined by combinations of the surface variables. The variables that proved

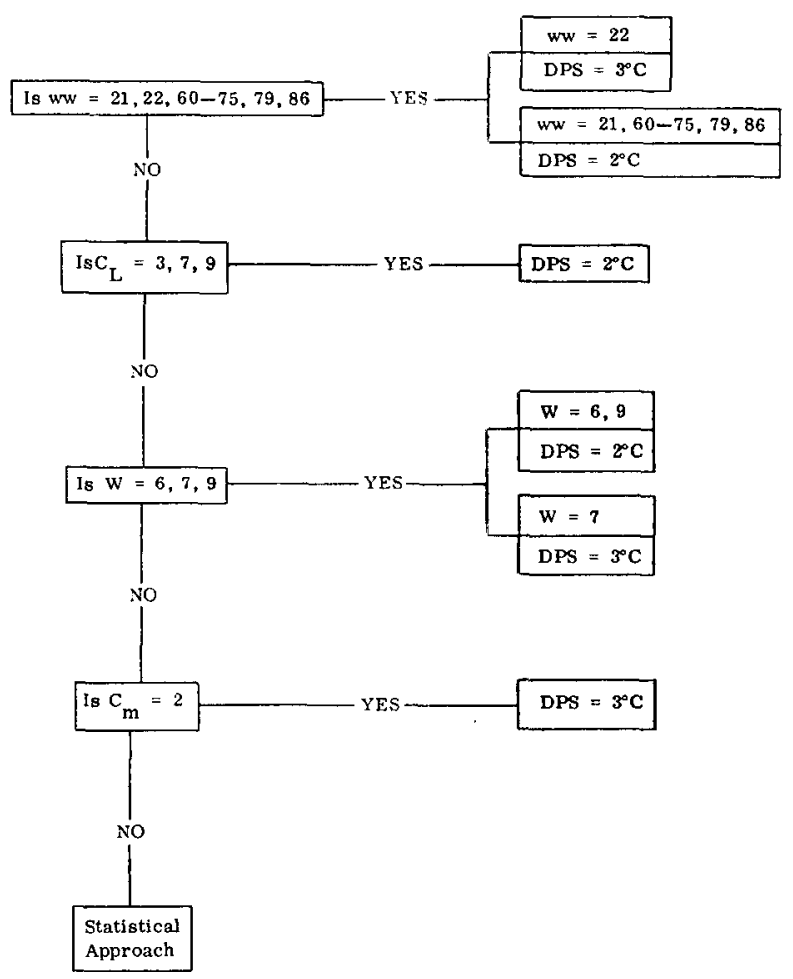

FIG. 3. 700-mb decision tree. 


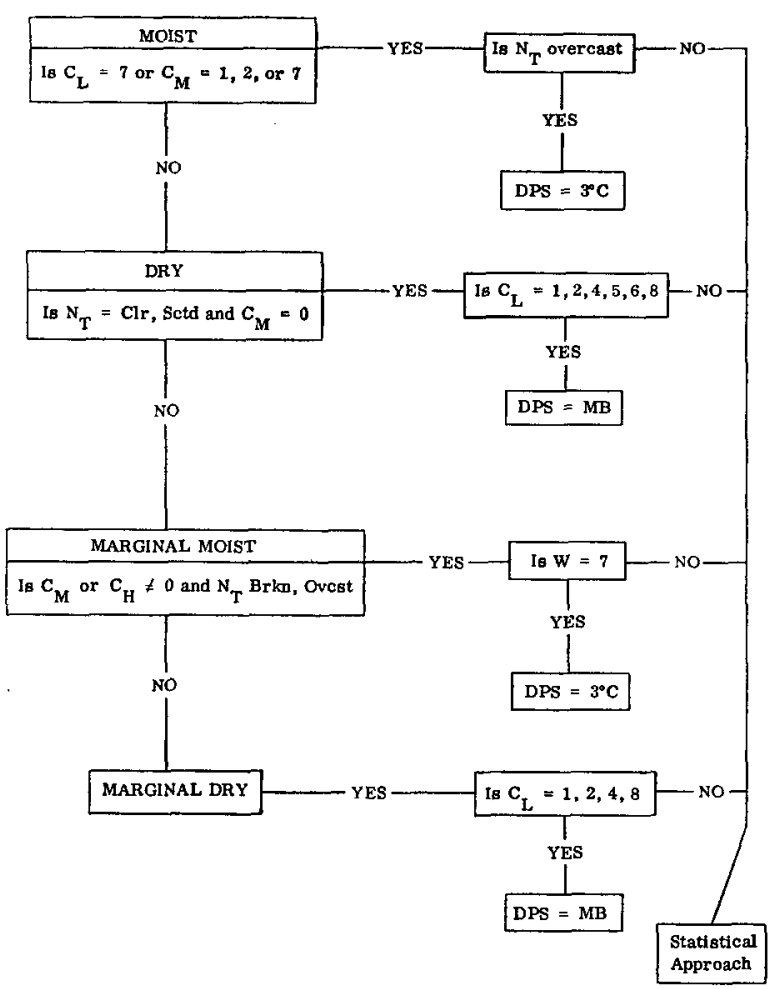

Fig. 4. 500-mb decision tree.

most satisfactory for this purpose are shown in the boxes on the left-hand side of Figs. 4 and 5. The total numbers of diagnoses (moist and dry) made at 500 and $400 \mathrm{mb}$ were 4962 and 6077 , respectively. The greater number of diagnoses at $400 \mathrm{mb}$ is due to the higher frequency of large DPS or motorboating cases at this level.

Independent data evaluation. The decision trees at all four levels were tested on an independent sample of approximately $\mathbf{5 5 0 0}$ cases representing every fifth time period (2$\frac{1}{2}$ days) from November 1961 to February 1962. The independent data results for all decision trees were comparable to the results obtained from the developmental sample.

\section{Statistical evaluation and results}

In the REEP technique (Miller, 1964), selected for the development of the diagnostic relationships with the residual samples, the specificand (DPS at a given level) and each potential specifier (surface variables) are transformed from raw variables to dummy variables. Dummy variables are obtained by dividing raw variables into two or more groups such that any numerical value within the raw-variable range of values will fall into one of the groups. Each of the two or more groups that are generated is a dummy variable. When the value of the raw variable is within the range of a given group (dummy variable), the dummy variable takes a value of 1 ; otherwise it is 0 . Table 4 gives the categories (dummy

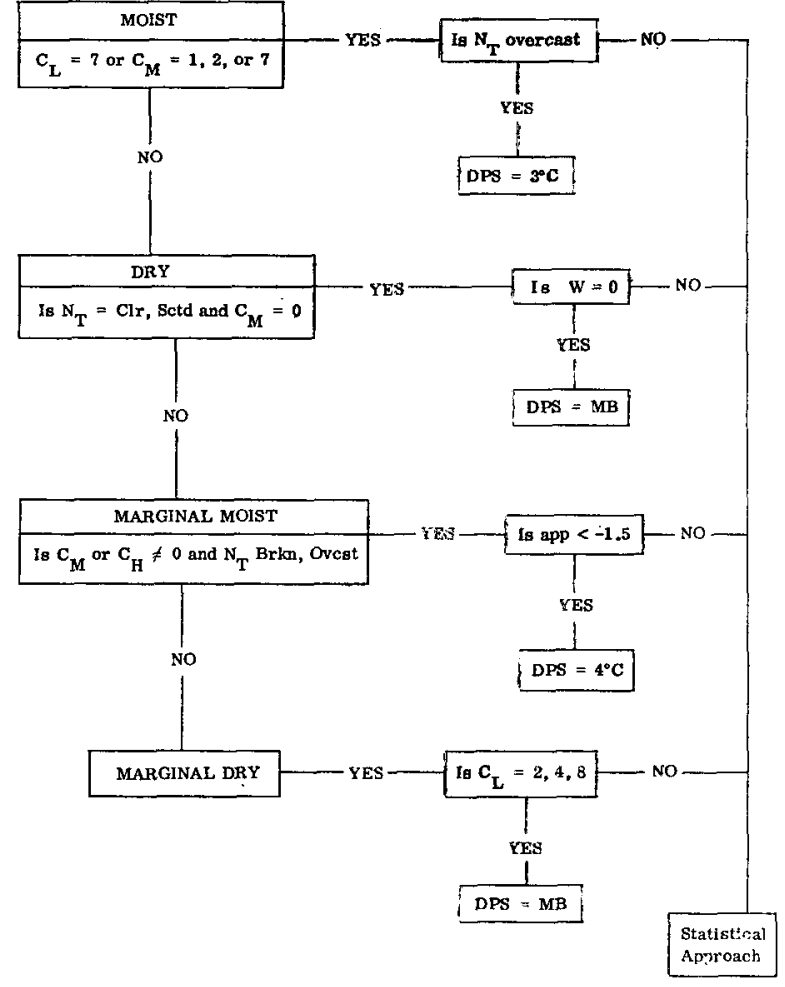

Fig. 5. 400-mb decision tree.

variables) of DPS used at each level in the REEP experiments.

In the REEP procedure, the surface dummy variables are screened objectively and a small subset are selected such that nearly all the predictive information in the entire set is retained [see Miller (1964)]. A separate multiple regression equation is developed for each category of DPS, and from each equation an estimate of the probability of occurrence of that category is obtained.

As shown in Table 1, all variables in the surfacesynoptic message through the pressure tendency group

TABLE 4. Dewpoint spread categories at $850,700,500$ and $400 \mathrm{mb}$.

\begin{tabular}{|c|c|c|}
\hline $\begin{array}{l}\text { Level } \\
(\mathrm{mb})\end{array}$ & $\begin{array}{l}\text { Dummy } \\
\text { variable } \\
\text { category }\end{array}$ & $\begin{array}{c}\text { Range of values } \\
\left({ }^{\circ} \mathrm{C}\right)\end{array}$ \\
\hline 850 & $\begin{array}{l}1 \\
2 \\
3\end{array}$ & $\begin{array}{r}0 \leq \text { DPS } \leq 5 \\
5<\text { DPS } \leq 10 \\
10<\text { DPS }\end{array}$ \\
\hline 700 & $\begin{array}{l}1 \\
2 \\
3\end{array}$ & $\begin{array}{r}0 \leq \mathrm{DPS} \leq 6 \\
6<\mathrm{DPS} \leq 14 \\
14<\mathrm{DPS}\end{array}$ \\
\hline 500 & $\begin{array}{l}1 \\
2 \\
3\end{array}$ & $\begin{aligned} & 0 \leq \text { DPS } \leq 7 \\
& 7<\text { DPS } \leq 16 \\
& 16<\text { DPS }\end{aligned}$ \\
\hline 400 & $\begin{array}{l}1 \\
2 \\
3\end{array}$ & $\begin{aligned} & 0 \leq \text { DPS } \leq 7 \\
& 7<\text { DPS } \leq 19 \\
& 19<\text { DPS }\end{aligned}$ \\
\hline
\end{tabular}


TABLE 5. 850-mb selected variables and associated coefficients.

\begin{tabular}{|c|c|c|c|c|c|}
\hline \multirow[b]{2}{*}{ Order } & \multirow{2}{*}{$\begin{array}{l}\text { Selected } \\
\text { variable }\end{array}$} & \multirow[b]{2}{*}{ Range of values* } & \multicolumn{3}{|c|}{ Coefficients of REEP equations } \\
\hline & & & Cat. 1 & Cat. 2 & Cat. 3 \\
\hline 1 & DPS & $10<$ DPS & -0.148 & -0.249 & 0.397 \\
\hline 2 & DPS & $0<$ DPS $<3$ & 0.132 & -0.109 & -0.022 \\
\hline 3 & $\mathrm{~h}$ & $8000 \leq \mathrm{h}$ (or no low cloud) & -0.142 & 0.015 & 0.127 \\
\hline 4 & $T$ & $T \leq-15$ & 0.130 & 0.007 & -0.137 \\
\hline 5 & $\mathrm{~T}$ & $-15<\mathrm{T} \leq 0$ & -0.052 & 0.110 & -0.058 \\
\hline 6 & $\mathrm{~N}_{\mathrm{T}}$ & 0 & -0.072 & $\quad 0.030$ & 0.042 \\
\hline 7 & DPS & $6<\mathrm{DPS} \leq 10$ & -0.095 & -0.017 & 0.113 \\
\hline 8 & ww & $0 \overline{2}$ & -0.057 & -0.011 & 0.068 \\
\hline 9 & app & $-3.1<$ app $\leq-1.6$ & -0.069 & -0.059 & 0.128 \\
\hline 10 & $\mathrm{~T}_{\mathrm{d}}$ & $-5<\mathrm{T}_{\mathrm{d}} \leq 1 \overline{0}$ & -0.045 & -0.021 & 0.067 \\
\hline 11 & $\mathrm{C}_{\mathrm{I}}$ & 5 & 0.098 & -0.055 & -0.042 \\
\hline \multicolumn{3}{|c|}{ Additive constants } & 0.433 & 0.370 & 0.197 \\
\hline
\end{tabular}

* Units as given in Table 1.

are considered in the statistical evaluation. It should be remembered that many variable types are missing, or nearly so, in the residual sample due to the application of the decision trees (Figs. 3-6); thus, the screened dummy variables differ for each level due to differences in the decision trees.

850-mb residual sample. The 850-mb REEP equations were developed from a residual dependent sample of 5328 cases and tested on an independent sample of 1267 cases. Table 5 gives the variables in order of selection, the range of values, and the coefficients of the REEP equation for each DPS category. The occurrence of a selected variable within a given range results in a contribution to the probability of occurrence of the $850-\mathrm{mb}$ DPS category as indicated by the coefficient. Thus, when the surface DPS is greater than $10 \mathrm{C}$, a strong contribution is made toward the probability of Category 3 (850-mb DPS $>10 \mathrm{C}$ ) occurring. When the surface DPS is $3 \mathrm{C}$ or less (second variable selected), moist conditions at $850 \mathrm{mb}$ are indicated. These first two selected variables simply reflect the strong positive correlation between moisture at the surface and at $850 \mathrm{mb}$. The sign and magnitude of the coefficients of the selected variables must be considered in light of the magnitude of the additive constant in the equation.

700-, 500- and 400-mb residual samples. The first eight dummy variables selected to diagnose DPS at 700 , 500 and $400 \mathrm{mb}$ are given in Table 6 [see Ball et al. (1956a) for the REEP equations]. Note that for all

TABLE 6. 700-, 500- and 400-mb selected variables.

\begin{tabular}{clll}
\hline \hline & \multicolumn{3}{c}{ Selected dummy variables* } \\
Order & \multicolumn{1}{c}{$700 \mathrm{mb}$} & \multicolumn{1}{c}{$500 \mathrm{mb}$} & \multicolumn{1}{c}{$400 \mathrm{mb}$} \\
\hline 1 & $\mathrm{C}_{\mathrm{M}}=0$ & $\mathrm{C}_{\mathrm{M}}=0$ & $0<\mathrm{T} \leq 15$ \\
2 & $15<\mathrm{T} \leq 30$ & $15<\mathrm{T} \leq 30$ & $15<\mathrm{T} \leq 30$ \\
3 & $0 \leq \mathrm{W} \leq 1$ & $0 \leq \mathrm{W} \leq 1$ & $\mathrm{~W}=2$ \\
4 & $0<\mathrm{T} \leq 15$ & $2 \leq \mathrm{C}-13$ & $\mathrm{C}_{\mathrm{M}}=0$ \\
5 & $0 \leq \mathrm{D} \mathrm{P} \leq 5$ & $\mathrm{~T} \leq-15$ & $10 \leq \mathrm{ww} \leq 12$ \\
6 & $-15<\mathrm{T} \leq 0$ & $70 \leq \mathrm{ww} \leq 75$ & $\mathrm{~N}_{\mathrm{T}}=\mathrm{sctd}$ \\
7 & $\mathrm{C}_{\mathrm{H}}=$ unknown & $\mathrm{ff} \leq 3$ & $\mathrm{~T}_{\mathrm{d}} \leq-25$ \\
8 & $1020<\mathrm{P}$ & $59 \leq \mathrm{Ww} \leq 69$ & $8 \leq \mathrm{W} \leq 9$ \\
\hline
\end{tabular}

* Units as given in Table 1. three levels, middle- or high-cloud types were selected. The cloud-type category "unknown" indicates a lower overcast. Also note that surface DPS was not selected as a specifier of 500 - or $400-\mathrm{mb}$ DPS, illustrating the decreasing correlation between moisture at the surface and moisture at higher levels.

Table 7 summarizes the dependent and independent data evaluations of the resultant REEP equations assuming a diagnosis is made in every case. The greater percentage of hits in diagnosing $400-\mathrm{mb}$ DPS reflects the large number of cases containing dry observed and diagnosed DPS. The individual contingency tables of observed and diagnosed 500- and 400-mb DPS indicate a tendency to over-diagnose dry conditions and underdiagnose moist conditions.

\section{Comparison and conclusions}

This approach used to diagnose upper-level DPS was not done without considering other alternatives. Thus, comparisons were also made of decision tree plus REEP vs REEP only, joint effect dummy variables vs "simple" dummy variables, and single-station data vs network data.

It was found that the approach described in this paper (decision tree plus REEP) resulted in many more diagnoses than the REEP only approach; that the use of joint-effect variables did not increase diagnostic skill for this problem; and finally, that the increase in diagnostic skill using a network approach was of questionable value considering the complexity of using a network diagnostic approach on a hemispheric scale.

In conclusion, the combination of the decision-tree and REEP techniques gives an acceptable method of

Table 7. Residual-sample results (all levels).

\begin{tabular}{|c|c|c|c|c|}
\hline \multirow{2}{*}{$\begin{array}{l}\text { Level } \\
\text { (mb) }\end{array}$} & \multicolumn{2}{|c|}{ Dependent data } & \multicolumn{2}{|c|}{ Independent data } \\
\hline & $\%$ hits & Cases & $\%$ hits & Cases \\
\hline 850 & 51.3 & 5328 & 52.0 & 1276 \\
\hline 700 & 52.8 & 7668 & 53.6 & 1766 \\
\hline 500 & 50.3 & 7020 & 49.4 & 1618 \\
\hline 400 & 60.3 & 5112 & 60.7 & 1164 \\
\hline
\end{tabular}


estimating upper-level moisture from surface observations. The diagnostic information obtained from the decision trees is of relatively high quality while that obtained from the REEP equations is of varying quality as reflected by the associated probabilities. The percentage of surface observations that will yield useful upper-level humidity diagnoses varies with season, pressure level, and minimum probability required for a REEP diagnosis to be acceptable. However, it is generally between 25 and $50 \%$ of all surface stations. Therefore, on a hemispheric basis between 1000 and 2000 additional estimates of humidity are available for an analysis. The problem that remains is the incorporation of these data with available radiosonde observations into an objective analysis of DPS. Such a technique is presented and evaluated in a companion paper in this JouRNAL by Ball and Veigas (1968).

The diagnostic relations described here were developed from hemispheric data from the winter season. A comparable set of relationships has been developed from hemispheric data, including a period from late August through October (Ball et al., 1965b).

Acknowledgments. The surface-synoptic and upper air data used to develop the diagnostic relationships were supplied by the 3rd Weather Wing, Global Weather Central, Offutt AFB, Nebr. The planning of the research to develop diagnostic relationships was done jointly with 3rd Weather Wing personnel.

Outstanding IBM 7090 programming support was supplied by Miss Jane Goode of the United Aircraft Corporation Research Laboratories. Miss Sally Swan- son of the Travelers Research Center performed IBM 1620 programming and extensive data tabulations. The authors are grateful for each of the above contributions.

\section{REFERENCES}

Air Weather Service, 1961: Analysis of clouds with aid of raobs: Use of the skew $\mathrm{T}, \log \mathrm{p}$ diagram in analysis and forecasting. Vol. 1, Radiosonde Analysis, Air Weather Service Manual 105-124, Chap. 7.

Ball, J. T., D. A. Chisholm, P. V. Luty and K. W. Veigas, 1965a: The diagnosis of upper-air humidity from surface observations. Tech. Rept. 7463-151, The Travelers Research Center. Inc., Hartford, Conn. (ESD-TR-65-1, 433L System Program Office, ESD, Air Force Systems Command, Bedford, Mass.., $184 \mathrm{pp}$.

$-\longrightarrow,-$ and $-1965 \mathrm{~b}:$ The objective analysis of humidity. Tech. Rept. 7463-181, The Travelers Research Center, Inc., Hartford, Conn. (ESD-TR-65-15, 433L Systems Program Office, ESD, Air Force Systems Command, Bedford, Mass.), 105 pp.

- - and K. W. Veigas, 1968: The analysis of upper-level humidity. $J$. Appl. Meteor., 7, 620-625.

Essenwanger, O., 1962: Frequency of cloud height layers for Berlin (Tempelhof). J. Appl. Meteor., 1, 560-569.

Mason, B. J., and B. P. Howorth, 1952: Some characteristics of stratiform clouds over Northern Ireland in relation to their precipitation. Quart. J. Roy. Meteor. Soc., 78, 226-230.

Miller, R. G., 1964: Regression estimation of event probabilities. Tech. Rept. 7411-121, The Travelers Research Center, Inc., Hartford, Conn., 153 pp.

Mook, C. P., 1955: Stratiform cloud thickness associated with drizzle. Bull. Amer. Meteor. Soc., 36, 490.

Smagorinsky, J., 1960: On the dynamical prediction of large-scale condensation by numerical methods. Physics of Precipitation. Geophys. Monogr. No. 5, Washington, D. C., Amer. Geophys. Union, p. 71. 